\title{
Acute Myocardial Infarction Type
}

National Cancer Institute

\section{Source}

National Cancer Institute. Acute Myocardial Infarction Type. NCI Thesaurus. Code

C118936.

A classification or description of the acute myocardial infarction. 